\title{
A Science of Signals: Einstein, Inertia, and the Postal System
}

\section{Citation}

Canales, Jimena. 2011. A science of signals: Einstein, inertia, and the postal system. Inertia. Special Issue. Thresholds 39: 12-25.

\section{Permanent link}

http://nrs.harvard.edu/urn-3:HUL.InstRepos:8588390

\section{Terms of Use}

This article was downloaded from Harvard University's DASH repository, and is made available under the terms and conditions applicable to Other Posted Material, as set forth at http:// nrs.harvard.edu/urn-3:HUL.InstRepos:dash.current.terms-of-use\#LAA

\section{Share Your Story}

The Harvard community has made this article openly available.

Please share how this access benefits you. Submit a story.

\section{Accessibility}




\section{A Science of}

Signals

Einstein, Inertia and the Postal System

\section{Jimena Canales}

What do the speed of light and inertia have in common? According to the famous physicist Arthur Eddington, who led the expedition to prove Einstein's Theory of Relativity, they had a lot in common: "[the speed of light] is the speed at which the mass of matter becomes infinite," where "lengths contract to zero" and - most surprisingly - where "clocks stand still." The speed of light "crops up in all kinds of problems whether light is concerned or not," reaching all the way into the concept of inertia. In Einstein's work, the most seemingly ephemeral and fleeting of things - light - could not escape from the grasp of inertial and gravitational forces.

From 1900 onward Einstein became acutely concerned (personally and professionally) with communications media, and, in particular, with their speed. Could love be sent through the mail?, wondered Einstein. Did kisses arrive at their destination?, asked his contemporary, Franz Kafka. How strange, both men remarked as they perused complicated train schedules and jotted down times and places in their notes and letters, that nearly contiguous places were so far apart once all the stops, bureaucrats and customs officers were overcome, while other distant places could be so easily reached. "How on earth did anyone get the idea that people can communicate with one another by letter?" wrote Kafka to his lover in the 1920s. During those same years, Einstein ended a letter expressing a similar concern: "I won't write any more about it, in order not to confuse things even further."

Einstein's famous 1905 theory of relativity paper dealt centrally with the problem of sending and receiving time signals. As such, it fit within research on time coordination that involved many other scientists. ${ }^{3}$ But soon after its publication, scientists started to ask how the exchange of "light signals ... through empty space" investigated by Einstein fit with other forms of communication, including those for determining time but not limited to them. Einstein expanded his work from its initial focus on time signaling to signaling in general. In the process, he learned that neither love nor time could travel at speeds faster than that of light.

Einstein often claimed that his theory seemed strange only because in our "everyday life" we did not experience delays in the transmission speed of light signals: "One would have noticed this [relativity theory] long ago, if, for the practical experience of everyday life light did not appear" to be infinitely fast. ${ }^{4}$ But precisely this aspect of everyday life was changing apace with the spread of new electromagnetic communication technologies, particularly after World War I. The expansion of electromagnetic communication technologies and their reach into everyday life occurred in exact parallel to the expansion and success of Einstein's theory of relativity. Kafka, who used similar communications system as Einstein and whose obsessive focus on "messengers" and their delays paralleled Einstein's focus on "signals" and their delays, described the radical change he was seeing around him in the 1920s:

Humanity ... in order to eliminate as far as possible the ghostly element between people and to create a natural communication ... has invented the railway, the motor car, the aeroplane. But it's no longer any good, there are evidently inventions being made at the moment of crashing. The opposing side is much calmer and stronger; after the postal service it has invented the telegraph, the telephone, the radiograph. The ghosts won't starve, but we will perish. ${ }^{5}$

\section{From Time Signals to Signals In General}

Einstein's 1905 relativity paper was an investigation into the time taken by "a light signal" to reach an observer "through empty space." ${ }^{\prime \prime}$ It initiated an unprecedented overhaul of physics that had not been seen since the time of Newton. How did an apparently simple account about basic, procedural techniques pertaining to the exchange of "light signals" become so much more? And how did it efface its lowly origins? In 1905 the "light signals" referred to by Einstein were very elementary, especially compared to what they would become in the decades that followed.

Contemporary physicists and even philosophers often understood Einstein's work as a science of signals with implications for telecommunication technologies. Descriptions of Einstein's work as a study of light signals abounded during 
the period of its emergence. The philosopher and mathematician Alfred North Whitehead, one of the most important thinkers to challenge the theory, called it both "signaltheory" and "message theory." The connection of relativity theory to telecommunications science and technology followed three stages. While they first appeared in 1907 as constitutive, Einstein later described them in 1910 as consequential. Eventually these connections were completely effaced, to the point that most historians, physicists and philosophers forgot all about them.

Einstein's theory flourished in the era of electromagnetic communication technologies and debates over its validity were argued in terms of the possibilities and limitations of long-distance communication. While still working at the Patent Office, which was being flooded with applications for new wireless communications technologies, he corresponded with his colleague Wilhelm Wien to determine if the exchange of light signals described in his relativity paper applied to other forms of information-transfer signals. His letters now described problems in physics in terms of the general scenario of signal sending ("emanation") and reception ("perception"): "Let A be a point from which electromagnetic influence can emanate, and $\mathrm{B}$ a point in which the influence emanating from A be perceived." Einstein followed the results of Emil Wiechert, who determined that the velocity of an "optical signal" should always be less than the speed of light. This was true, Einstein claimed, "in any medium." 9

Einstein soon started defining "signaling" in physics in the way it was used by the communications industry, and distinguishing the term from previous definitions that included periodic and predetermined signals. Previously, the term "signal" was used frequently in physics to denote both a symbol and a sign, including periodic and predetermined causes, but Einstein increasingly defined it in narrower terms: as a communications signal.

During the second half of the nineteenth century, the famous German scientist Hermann von Helmholtz had urged his followers to consider the world as a system of signs; now Einstein urged his colleagues to think of it in terms of signals. In 1907, Einstein explained to a colleague that relativity theory was concerned with communication signaling - and not with other types of signs or signals:

I now designate the kind of velocity that, according to the theory of relativity, cannot be greater than the velocity of light in a vacuum as "signal

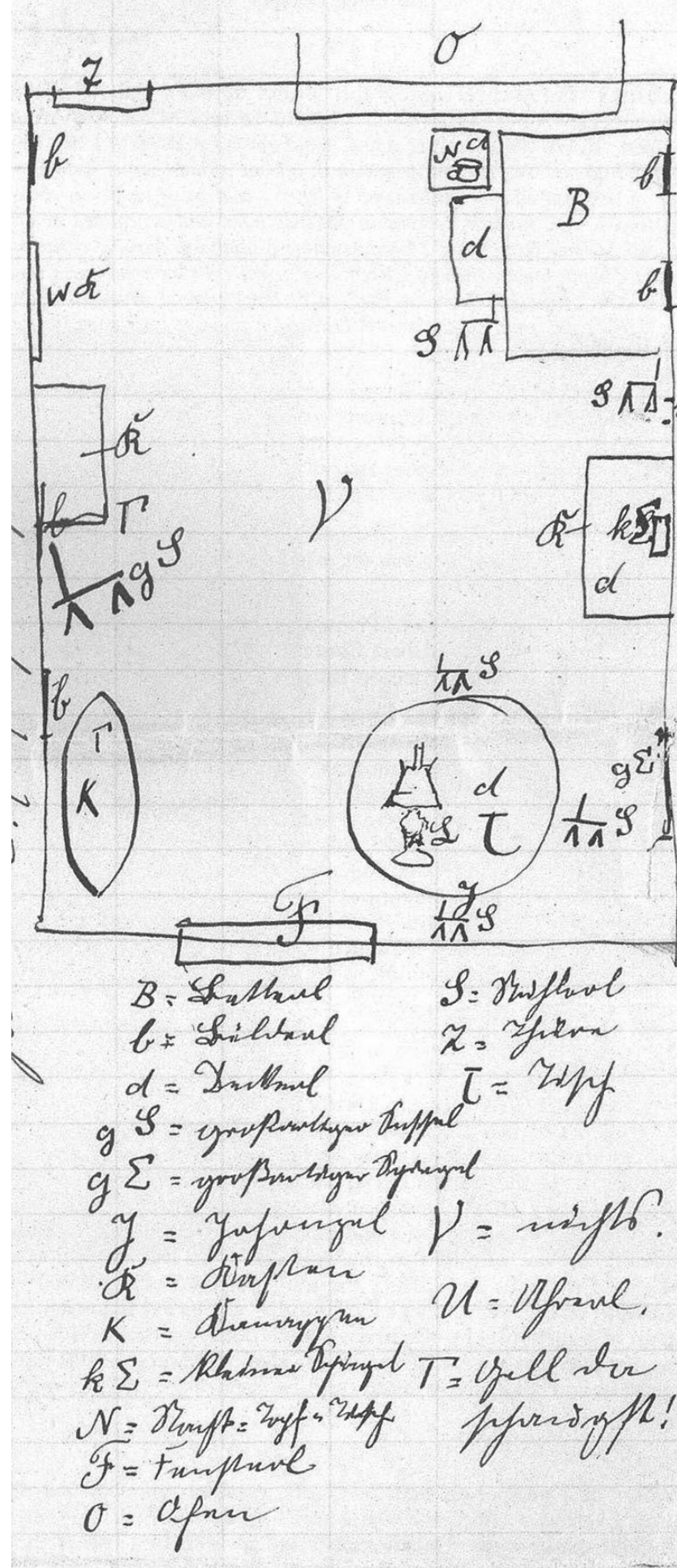


velocity." This is a velocity which a one-time (not regularly recurring) influence, which is not yet determined by past electrodynamic processes, is propagated; thus, we are dealing here with the propagation of an influence that could, for example, be used for sending an arbitrary signal. The propagation velocity ... in your analysis refers to a periodical process (periodical amplitude change, not an amplitude change of the most general kind. $)^{10}$

From that time onward Einstein's notion of signal was one which could be "arbitrary" and "one-time (not regularly recurring)" of "the most general kind" and which was "not yet determined by past ... processes." He focused on "the propagation of an influence that could, for example, be used for sending an arbitrary signal," which was different from "a periodical process." 11

Einstein's theory of relativity was based on a particular notion of observation-based science, one that considered "observation" in terms of light sent and received, and which contrasts starkly with how it was defined at other historical periods..$^{12}$ His descriptions of "simultaneity" explained, with precision, the behavior of rays of light meeting at one source at the same time: "a coincidence at once spatial and temporal on the retina of the observer." ${ }^{13}$ His work was concerned with a particular form of measurement - one which differed significantly from most micrometrical measurement techniques employed during the previous century. ${ }^{14}$ Measurement, for Einstein, was largely an ascertainment of the departure and arrival of signals. ${ }^{15}$

At the same time that Einstein expanded his work from one about time signals to one about general telecommunication signals, he underlined his break from previous interpretations of relativity theory, most notably from those of Hendrik Lorentz, who had developed the famous equations later used by Einstein. "A sufficiently sharpened conception of time was all that was needed to overcome" most of the difficulties plaguing previous interpretations of relativity theory ${ }^{16}$ Einstein reinterpreted the dilation of times predicted by relativity theory as real temporal effects, which were in no respect secondary or apparent in comparison to time in general. Expanding the meaning of the theory of relativity from a narrow one that dealt with clock time and the exchange of time signals to one that involved communication signals in general was necessary for Einstein's expansion of the notion of time - from clock time to time in general.

\section{"Signal-theory"}

From 1905 to 1907 Einstein's work changed from being an investigation of time signals to signals in general, but by 1910 Einstein reframed his research in yet another way. Its implications for signaling were described as a "consequence" of a much broader physical theory - and a profoundly counterintuitive one at that. Conditions necessary for sending or receiving signals were what "follows immediately" from his theory - not its starting point. Einstein described the inability "to send signals that would travel faster than light in a vacuum" as a "consequence, as strange as it is interesting" of his theory. ${ }^{17}$ Not everyone was convinced that this "consequence" followed necessarily. An audience member in one of Einstein's lectures protested that "he always comes to perceive the world around us by way of light signals." 18

"Signal-theory" is what "we will call it," wrote Whitehead referring to Einstein's theory of relativity. ${ }^{19}$ Whitehead's reading of Einstein's theory (and of what he considered to be its main inadequacies) centered intently on its relation to communication technologies. He chastised Einstein for giving an unwonted importance to light signals over others. He agreed that "light signals are very important elements in our lives," but nonetheless felt "that the signal-theory somewhat exaggerates their position." Whitehead stressed the role of other messaging technologies which he saw around him, reminding readers that "there is the transmission of material bodies, the transmission of sound, the transmission of waves and ripples in the surface of water, the transmission of nerve extension through the body and innumerable other forms which enter into habitual experience." His verdict and critique of Einstein's focus was clear: "The transmission of light is only one from among many" alternative ways of sending "physical messages from place to place." 20

Whitehead understood that the most important conclusions of relativity arose because light "was our quickest system of signals." ${ }^{21}$ Yet, he argued that a "system of signals" should not be elevated to a theory of the universe. In contrast to Einstein, Whitehead stressed the connections of relativity to current technical limitations for signaling, and aimed to develop his own version of relativity in a way which was no longer so intensely dependent on 
them. Contemporary technological limitations in signaling speed were the reason why the speed of light appeared as a constant in Einstein's theory. That is why "we are driven to the convention that light, as our quickest system of signals, is moving with uniform velocity." ${ }^{22}$ While Whitehead understood and accepted the radical conclusions of Einstein's theory with all its paradoxes, he nonetheless turned the physicist's argument completely on its head. Einstein started his argument by insisting that the constancy of the speed of light was a universal fact of nature; Whitehead started his by noting that it was, to that day, the quickest way of sending signals. In doing so, he placed the contemporary reality of telecommunication technologies of his era at the origin of our relativistic understanding of time.

Whitehead's account of relativity echoed with the views of many others. "The Einstein rules" were clear: "just giving and receiving signals," explained the American philosopher William Montague, who similarly did not believe that lessons about the transmission of light signal should be extended to a theory of the universe. ${ }^{23}$ "Einstein's 'light' is the most wonderful thing in the world," he mocked. ${ }^{24}$ The French scientist and philosopher Gaston Bachelard, another contemporary of Einstein, remarked on how current determinations of the speed of light, something so directly tied to wireless communications, emerged as much more. Instead of being a "reality found through experiment" it was "affirmed by a rule": "In effect, in Relativity, the speed of light does not appear as a reality that was found through experiment, but rather as a reality affirmed by a rule." ${ }^{25}$ The philosopher DeWitt H. Parker limited the significance of the theory of relativity to a science of messages, claiming that "relativity theory gives an absolutely correct picture with regard to the messages...."26

The physicist Sir Oliver Lodge, who made important contributions to the science of telegraphy (including wireless) became a strong critic of the philosophical underpinnings of relativity. In particular, he criticized Einstein's focus on light waves in terms of their potential for information transfer. "The mere reception of information," he argued, was given too much importance in Einstein's work: "It is true that these waves are among our methods of receiving and conveying information; but too much attention may be paid to the mere reception of information." ${ }^{27}$ Reception of an event, according to Lodge, should not be confused with the event itself, and he proceeded to criticize those who "speak as if the duration of the event could be extended by merely delaying the reception of the news at its end." ${ }^{8}$ Einstein's position, wrote Lodge, led to an absurd result: “as if we could prolong a man's life by evading the tidings of his death; and might be entitled to say, without absurdity, that a man who died at seventy had lived seventy-one years and a lot of miles, if we had travelled so far that a messenger took a year to reach us."29 A few years earlier, in 1917, Kafka wrote the story "The Great Wall of China," which described a similar situation. Because of the long transmission time of messages across the great nation, "in our villages, emperors long since dead are set on the throne."

Although many other commentators followed Whitehead, Lodge, and others in investigating the theory's relation to signaling technologies, many of them did not consider that aspect of Einstein's work as limiting. After World War I, the theory's connection to communication technologies continued to be mentioned periodically by both scientists and philosophers, but (for the most part) these connections were increasingly deemed to be consequential rather than constitutive. Eventually, they slipped into the background until they largely became invisible.

Even scientists like Eddington, who stressed the most theoretical and cosmic aspects of relativity theory over the most mundane, employed the language of communications technology in order to explain and understand it. Eddington described Einstein's views of time in terms of information and noise. "The phrase true time is a "meaningless noise," he explained. ${ }^{30} \mathrm{He}$ confronted head-on the prickly accusation of the preponderant importance given by Einstein to signaling speed of light effects, answering the "objection" that "is sometimes raised to the extravagantly important part taken by light-signals and lightpropagation in Einstein's discussion of space and time." ${ }^{31}$ He explained how nothing "capable of being used as a signal can travel faster than 299,796 kilometers a second."32 The theory of relativity perfectly explained "the consequences of being able to transmit messages concerning events" from one place to another. ${ }^{33}$ The world described by Einstein was the way it was, explained the astronomer, because "signaling is only possible" in certain conditions and not in others. ${ }^{34}$

Yet Eddington followed Einstein himself in effacing the theory's relation to media technologies while, paradoxically, he used them as illustrative examples. He included his statements about "wireless messages" only in a footnote to 
the published lecture, and not in the lecture proper. While Whitehead had criticized the extension of a science of light signals to a general science of the universe, Eddington welcomed this extension by introducing some additional examples.

The assessment of relativity theory by Louis de Broglie, the famous scientist who contributed to the development of quantum mechanics, was almost exclusively in terms of telecommunications. This point of view perhaps came naturally to de Broglie, who, upon entering the army during World War I, worked in the wireless military service unit that used the Eiffel tower for military wireless transmission under General Gustave-Auguste Ferrié who collaborated with Marconi since in 1899 and who in 1908 placed new antennas on the tower to increase the range of radiotelegraphic transmission from $400 \mathrm{~km}$ to 6,000 $\mathrm{km}$. De Broglie framed Einstein's contribution as proving the "absence of signals which travel at infinite speed" and realizing "the fact that no signal can travel with a speed greater than that of light in a void." ${ }^{35}$

The philosopher Hans Reichenbach also explained Einstein's theory by reference to signaling technologies: "Einstein's relativity of simultaneity is closely associated with the assumption that light is the fastest signal." ${ }^{36}$ It would not hold in a world with "no upper limit for the speed of signals." ${ }^{37} \mathrm{He}$ also used the example of the telephone to illustrate how we could grow "accustomed" to the reality described by Einstein. "If a telephone connection with the planet Mars were established," he explained, "we would have to wait a quarter of an hour for the answer to our questions." If our communication technologies functioned in that way then "the relativity of simultaneity would become as trivial a matter as the time difference between the standard times of different time zones today." ${ }^{38}$ His description of the Michelson-Morley experiment illustrated just how heavily he relied on theories of communication, while he nonetheless effaced these constitutive connections to communications technology. He went as far as describing the Michelson-Morley experiment as a telecommunications machine, that is, as an experiment about the speed of "signals." Reichenbach argued that "the assumption that light is the fastest signal" was "an idea which could not be conceived before the negative outcome of such experiments as that of Michelson." ${ }^{39} \mathrm{He}$ also echoed Einstein's own view that his theory was only difficult to understand because the enormous speed of light made it seem instantaneous: "Human beings, in whose daily expe- riences the effects of the speed of light would be noticeably different from those of an infinite velocity, would become accustomed to the relativity of simultaneity and regard ... [it] as necessary and self-evident." ${ }^{40}$

\section{Effacing Communications Technology}

Yet Reichenbach's reliance on communication technologies to understand and explain Einstein's theory was similarly relegated. His comprehensive philosophical understanding of "experiment" did not include a role for technology, let alone contemporary and especially commercial technologies. Einstein's work emerged from "an empiricism which recognizes only sense perception and the analytic principles of logic as sources of knowledge." In this general view, there was no place for media like the "telephone," which he, ironically, used to explain the theory. ${ }^{41}$

For many scientists, the constancy of the speed of light one of the central and most mystifying claims of Einstein's theory - was a mere technological fact related to current limitations in telecommunication technologies. Many considered that the value of the speed of light, often expressed in kilometers per second and stated in formulas simply as $c$, was so technical and so lacking in elegance (it did not even come close to being a nice round number or integer) that it was unfit to parade as a universal absolute.

Einstein disagreed. Even up to the last years of his life, Einstein combated critics by stressing how the seeming arbitrariness of the number $c$ could be eliminated. If the unit of seconds from the relativity equations was replaced by "the time in which light travels $1 \mathrm{~cm}$ " it could be made to equal one. ${ }^{42}$ Once the arbitrariness in the number $\mathrm{c}$ was made to disappear, the constancy of the speed of light appeared much more natural, logical, necessary and universal. But either recalculated to equal 1 (by replacing the unit of seconds with the time taken by light to travel $1 \mathrm{~cm}$ ) or in its traditional (yet messier) kilometers per second format, the speed of light was what it was in the first decades of the century: the speed of the fastest communication technologies of the era.

\section{A Universe of Signals}

When Einstein famously said that "we cannot telegraph into the past," this often-repeated sentence was considered to have profound metaphysical and cosmological consequences. ${ }^{43}$ But this statement was also a simple comment about a practical limitation of the communications technologies of his era. 
Einstein, by reference to signals, and their path and their reach, overhauled concepts of time and space. By reference to them, he recalculated the shape and size of the universe; understood gravitational forces; determined the relation between cause and effect; and differentiated the past from the present and future.

In Einstein's universe all actions had to be carried by a signal. He forcefully criticized Newton's theory because of its reliance on the concept of "action at a distance," a phrase that increasingly referred to Newton's uncritical notion of bodies (such as planets) acting on each other without offering any explanation for how actions were actually carried from one body to the other. Newton's universe was replete with actions at a distance. The mass of the sun, for example, mysteriously acted on the earth and produced its orbit. In the Newtonian universe the attraction between any two bodies was simply proportionate to their masses and to the square of the distance between them. Newton was not concerned with how these forces propagated or what sustained them. How, Einstein argued instead, were these forces transmitted exactly and at what speed? In "Einstein's theory," explained Lorentz, "gravitation itself does not spread instantaneously, but with a velocity ... that may be compared to that of light." ${ }^{44}$

One of the most revolutionary assertions of Einstein was that the universe was essentially curved. The idea that the shortest path between two points was not, as in Euclidean geometry, a straight line was directly connected to the universe's curved shape. How could a curve be the shortest path between two points? If the shortest path was defined as that travelled by an electromagnetic signal in the presence of a gravitational field, the result was indeed a curve. In Einstein's universe the distant and the close did not match with the faraway and contiguous. Kafka, at about the same time as Einstein, described places that, although next door to each other, were far since they could never be reached by a messenger.

Einstein and many of his interlocutors defined the relation between cause and effect in terms of signaling. Before Einstein's theory appeared, explained Paul Langevin, scientists thought that signaling could be instantaneous, that "a string to ring a bell ... permitted instantaneous signaling." 45 But even this "causal" effect took time to occur. The pulling of the string and the ringing of the bell were not simultaneous: "causality, whatever its nature, cannot propagate itself with a velocity greater than that of light. There should not exist a messenger or a signal that can travel at speeds greater than three hundred thousand kilometers per second." 46

As Einstein developed his work from one initially about clock signals to signals in general, he increasingly started to understand the difference between the past and the future in terms of signaling possibilities. He defined the past as the time of signal emission if compared against the time of reception. And the future was the time of reception if compared to the time of emission. There were no cases where a "signal would have arrived at its goal before being emitted: The effect would precede the cause." ${ }^{47}$ Eddington, similarly, explained that the past was only really past if it "would be possible for us to have already received a wireless message announcing its occurrence." 48

\section{Wires, Wireless and Radio}

Einstein's twentieth century world differed from the eighteenth century world of Newton in one essential respect: technologies of communication were radically different. Carriers of communication were no longer people and postal letters, but rather electromagnetic technologies: telegraph, telephone and radio. ${ }^{49} \mathrm{As}$ a consequence, communication was no longer connected to transportation networks and eventually outpaced them greatly. In the postal era, people and information travelled in vehicles; in the electromagnetic era, they did not. The rules of communication were radically new and these new rules were exactly the same ones that Einstein described and ascribed to the entire universe. The world of horse-drawn carriages and post was one where geography mapped onto territory; the world of steam, rail and telegraphy and was one which surpassed geographical obstacles through the exploitation of natural resources and cheap labor; the world of telegraph, telephone and wireless was Einstein's universe. In 1928 the poet and critic Paul Valéry described how telecommunications reached even the interior of private homes, in what seemed a veritable "reality home-delivery service." Valéry asked, "I don’t know if a philosopher has ever dreamt of a société pour la distribution de la Réalité Sensible à domicile." ${ }^{\circ 0}$

Light signaling technologies before the nineteenth century were mainly optical, and connected to the semaphore, which was used mostly for military purposes. By the middle of the nineteenth century a light signal referred as well to the signal of an electric telegraph. Along with telegraphy, the last decades of the nineteenth century were marked with the possibility of at least another type of 
electromagnetic transmission. Like the semaphore, it was optical and based on the transmission of light, but unlike the semaphore, the signal could not be seen with the naked eye. Like telegraphy, it involved electricity, but unlike telegraphy, transmission occurred wirelessly. Like X-rays, it was able to penetrate and cross bones, walls and all sorts of obstructions.

In 1887, the German physicist Heinrich Hertz saw an electric spark jump in a coil of wire when he passed electricity through another close-by coil. In 1894, Guglielmo Marconi transmitted dots and dashes across his garden. Around 1900, telegraph and telephone conversations only occurred for urgent business affairs. Until 1903 most wireless applications were still military. ${ }^{51}$ In 1905 , when Einstein published his famous paper, wireless transmission could only be used for the transmission of simple signals to a few highly specific places. Long-distance communications were mostly carried out through the post, although telegraph networks continued to expand. In 1907, a decade after the Bell telephone patents expired, Einstein could telephone some of his friends. Wireless transfer of voice occurred experimentally a few years later. Wireless time sending service became regular in Paris after 1910. When World War I broke out in 1914, research into wireless increased, creating a new demand for triode vacuum tubes (previously manufactured mainly in the U.S.). ${ }^{52}$ After 1914, Einstein used the telegraph for personal business and telephone calls started becoming more frequent..$^{53}$ By 1915, telegrams started to be sent by telephone wires, eliminating the need for telegraphy to remain an autonomous system. ${ }^{54}$ By the year 1920 the use of the telephone had won over the telegraph to the point that Einstein had a telephone installed in his house. ${ }^{55}$ Broadcast radio gained momentum after those years.

\section{Post}

In his early years, Einstein's own experience of signal transmissions was through correspondence and the postal system. At the turn of the century, he had to spend significant amounts of time away from his lover Mileva Marić, sending her letters that circulated in a similar postal system to the one used by Kafka to reach his lover, Milená Jesenská. After a period of silence, Einstein wrote to Marić: "Three days have passed without my having received a letter, and as many nights. But I am so firmly convinced that you wouldn't let me wait so long, that I definitely believe that the letter got lost," blaming the "negligent postal service." Information transfer was at mercy of the post: "All this I have already written, but who knows whether you received it." 56 For Einstein "they [letters] must substitute for wifery, parents, friends and company, and they can do it, too." ${ }^{57}$ But further separation from Marić made Einstein painfully aware of the limitations of the postal system. In addition to the delay of transmission, messages could cross: "But our correspondence, dear sweetheart, seems to be under an evil spell, seeing that you had not received my letter at the time you mailed yours. This is the $3 \mathrm{~d}$ one I am sending you." ${ }^{58}$ Fears of meddling in their relationship by others intervening with the postal system led Marić to send a "registered letter" out of fears that Einstein's parents would "take away a letter." ${ }^{59}$ At times the messages did cross, and at least once Marić wondered what happened to her letter: "Did it indeed get lost or did something else happen to it?" 60 Einstein was so aware of the postal system that he compared himself to a postal package. When he did not know where he was going to live while in Zurich he wrote: "Thus I, poor postal parcel, must wait until I get enlightened about the place of my destination." 61

In 1901 Einstein compared his spatial distance from Marić to the "astronomical distances" they were both studying as physicists. He remarked how only a "huge imagination" could overcome these distances - ever painfully aware of the limitations of communication technology of his era. For Einstein and Marić, who had studied and worked together in Zurich, the challenge of being together again was connected to their goal of finishing "their" work on relative motion: "How happy and proud I will be when the two of us together will have brought our work on the relative motion to a victorious conclusion!"62 In the same letter to Marić, Einstein explained that he was "working very eagerly on an electrodynamics of moving bodies, which promises to become a capital paper." ${ }^{63}$

The postal system enabled Einstein's romantic relationships. Einstein initially believed that "love" could be sent and received through the post. After receiving a letter from Marić, he wrote: "Thank you very much for your little letter and the true love that's in it." ${ }^{4}$ Letters, nonetheless, were not a perfect substitute for a person. Einstein remarked on the evident differences between writing to and being with someone: "Writing is stupid. Sunday I am going to kiss you orally." 65 Yet Einstein started to understand that his love for her was strengthened with distance: "You can't imagine how tenderly I think of you whenever we're 
not together, even though I am always such a mean fellow when I am with you." 66

By the time he was living with Marić as his wife, but having a long-distance affair with his cousin Elsa, Einstein continued to have doubts about compensating for distances by letter-writing. Letter-writing provided only a "miserable surrogate of reality." ${ }^{67}$ By the time he separated from his wife and was free to marry his lover, Einstein had become painfully aware that he preferred love at a distance. Vacillating on his promises to marry Elsa, he argued that "a little bit of distance in our external life will be sufficient to protect what has made life so wonderful for us now from becoming banal and becoming pale." 68

During the first decade of the twentieth century, writers at a distance from each other communicated what they were seeing by sending drawings or photographs through the post. In 1912 the first successful telegraphic transmission of photographs from two distant European cities had taken place, but these technologies were only used for emergency "wanted" persons. Television was decades away.

Einstein repeatedly expressed a desire to see across distances: "If only I could peep through the keyhole!" he wrote to Marić from Milan. He also repeatedly wrote about the difficulties in sending images and photographs across long distances, which he did through post. In September 1900 after their time apart was nearly coming to an end, Einstein sent Marić a drawing of his foot: "I am finally sending you the sketch of my gigantic little foot ... since you have such a huge imagination and are used to astronomical distances, I believe that the accompanying work of art will suffice!"69 Imagination was the only way to complement the deficiencies of the postal system for the transmission of images, and it was grossly imperfect. In a 1901 letter to Marić, Einstein asked, "Why don't you make me a drawing of it [her figure], a really beautiful one!" Einstein's desire to see across distances intensified after the birth of his daughter Lieserl while he was still away: "I love her so much and I do not even know her yet! Couldn't she be photographed once you are totally healthy again?... When you feel a little bit better, you must make a drawing of her."70 To Marić, he sent a sketch of his room so that she could see what it was like [Figure 1].

To satisfy his lover Elsa while away, his only option was to send her a photograph of him by post as some sort of substitute: "I will try to find a picture of myself for you. I would prefer to come in person, but...."71 The photograph sent "did not arrive" and "then the Prague photographer
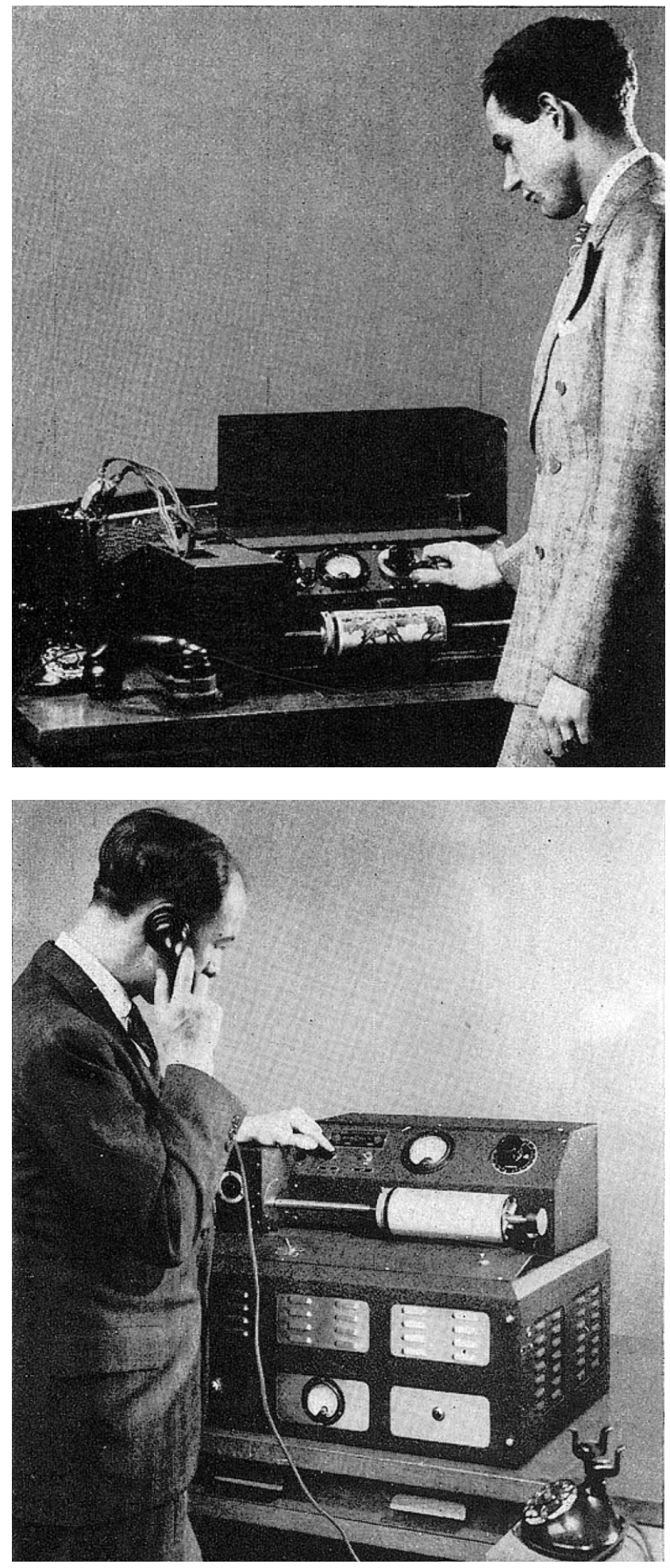
wrote to me, but the letter - did not arrive. This puts an end to my credulousness." ${ }^{22}$ When his son received a photograph of his father in the post after a long period of not being able to see him, he wrote to his father: "It is good that photography has been invented these days, since thus at least we get to see you." 73

During the first decade of the twentieth century, Einstein repeatedly wrote with frustration (and at least one time, regarding a possible reproach from his father, with satisfaction) about the inability to hear distant voices. While he wanted to be with Marić, he did not want to see his father, who did not approve of his girlfriend, and was already preparing a sermon against her: "Papa has now also written me a sermonizing letter for the time being, but he promised me that the main thing will follow orally." When commenting with undisguised excitement about when his friend Maurice Solovine was going to arrive, he explained: "Solovine is not yet within hearing distance, but he is bound to come soon." 75 During those years letters appeared secondary to speech, which for the most part was still attached to a person's body.

In the age of telephone and telegraph, Einstein continued to use the postal system, but he considered its advantages less in terms of the transmission of letters or people, than of goods without people. During his involvement with Elsa almost a decade after his relativity paper, the post and its delays took even more significance, but the significance was now different. Both text and voice could be sent through the telegraph and telephone. By then, Einstein no longer despaired about the difference between hearing and writing, but about being able to eat her cooking, which she was, fortunately, able to send by post. He became addicted to goose cracklings that his lover sent in the mail: "How good they are! Just now I have one in my beak and think with delight of the dear cook who, on top of her exciting undertakings, also has the heart and mind for a thing like this." But they further rubbed in the limitations of longdistance relationships, between letters, food, and flesh. "You pinch me with your letters but stroke me with goose cracklings," he despaired. ${ }^{76}$ One sad day in Zurich "all that arrived was the cover box with a few great-smelling grease stains." Einstein lost his patience: "But if I could seize that scoundrel of a postal worker by the scruff of his neck!" 77

Einstein's confidence in the postal system started to falter a few years before World War I broke out and declined sharply thereafter. By 1915 "the question of time" was not one that could be solved by exchanging letters. When the difference between his view of relativity and that of Hendrik Lorentz, who had developed the basic relativity equations used by Einstein, was reaching a point of crisis, Einstein was clear that the disagreements could not be solved through the post: "Finally, as far as the question of time is concerned, we are scarcely going to be able to debate this effectively by letter. I shall be glad to come to Holland." " The "question of time" was in fact not resolved through correspondence. In 1920, when trying to solve a practical issue pertaining to him getting his violin from Elsa, he gave up discussing it by letter: "I won't write any more about it, in order not to confuse things even further."79

During these same years, Kafka wrote "written kisses don't reach their destination," revealing that he was noticing some of the same aspects of communication technologies that Einstein was. In the face of electromagnetic alternatives, postal communication appeared much more secondary than the telegraph and telephone.

Kafka even asked where the strange idea that people could communicate by letter had come from..$^{80}$ The emergence of this idea as a question was unthinkable in the era of post-communication between people through correspondence was taken for granted. But in the same letter Kafka described emerging alternatives: "the telegraph, the telephone, the radiograph." In the face of alternative electromagnetic communication, the concept of communicating through texts started to emerge as quite strange. At the same time, the word "media" started to gain more and more currency. Einstein had titled his famous relativity theory paper "on the electrodynamics of moving bodies," but soon the physicist Hermann Weyl, one of the theory's first popularizers, found it more fitting to refer to it as a work on the "electrodynamics of moving media." 1

\section{Einstein's Rules of Traffic}

In the early years of the century train travel was the preferred means for bringing two people in contact with each other physically. Einstein's early letters were riddled with meeting times, often in railways stations: "We'll meet Monday at 6 o'clock at the tower," he wrote to Marić. Perhaps he meant under a clock tower? ${ }^{82}$ Train travel had a particular significance for Einstein and his lovers, first with Marić, then with Elsa, and for a brief period for the three of them. He feared an encounter between the wife and his "friend" simultaneously in the same train station. When he started to have an affair with his cousin Elsa, 
train stations and train speed became even more important: "Now I can't even pick you up at the train station and take you into my arms," he lamented to her, because "my wife is returning a few hours before you to make a last attempt at preventing the divorce." ${ }^{3}$ At a railway station in Berlin Einstein bid goodbye to his marriage and family: "The last battle has been fought. Yesterday my wife left for good with the children. I was at the railway station and gave them a last kiss. I cried yesterday, bawled like a little boy yesterday afternoon and yesterday evening after they had gone." 84

Railway stations were the place where two people previously separated by a distance could see and hear each other. Meeting, seeing and hearing were linked; vision, voices and people were all connected through railway technologies.

Shortly after Hertz's discovery, scientists were quick to notice that the transmission occurring wirelessly from one electric coil to another did not follow the same rules under which transportation technologies operated to carry texts, people and goods in the post and other vehicles. To explore the differences, from 1911 onward Einstein frequently turned to examples of moving vehicles, cabinets or boxes containing an atom or a person inside, that sometimes had windows and sometimes did not, which sometimes moved up and other times down, or forwards or backwards, accelerated or at constant speeds. Einstein's claim in his General Theory of Relativity that there was no difference between gravitation and acceleration was illustrated by explaining that the effect of being pushed to the floor when an elevator ascended was of the same nature as the effect of being pushed to the ground everyday by the earth's gravitational pull. When Einstein completed his general theory he described something similar to an elevator, but which was literally an experiment with a "man in a spacious chest resembling a room" hooked to a string which could raise or lower it. Lorentz, describing Einstein's theory in 1919, framed one of Einstein's contributions as “The Earth as a Moving Car." Lorentz agreed with Einstein: "we may compare the earth with such a moving vehicle," explaining how "everyone knows that a person may be sitting in any kind of a vehicle without noticing its progress, so long as the movement does not vary in direction or speed." ${ }^{5}$

But when Einstein turned to the study of moving vehicles to expand his theory of relativity from a special to a general case, the rules for understanding the move- ment of these vehicles were radically different than they had been before the advent of competing electromagnetic forms of communication. When Einstein's “rules” were directly applied to transportation vehicles such as automobiles, certain results appeared absurd. William Montague mockingly compared "the world of Einstein to a country ruled by a Mad Dictator. The Dictator besides being mad is passionately fond of motoring. He drives everywhere, and always at the tremendous speed of $186,000 . " 86$ The country of the Mad Dictator had strange rules: "If any speedometer fails to record the Dictator's speed as constant relative to the citizen's own speed, no matter what that may be, it is known to be wrong and is immediately confiscated." ${ }^{7}$ In this world, a world that, "when unequals are added to equals the results are equal" and "if two and two were put together in such a manner they might make four ... the law called for only three." 88 Montague did not accept Einstein's theory; he nonetheless successfully explained just how absurd it would look when applied to a universe of mail (vehicles) rather than to the one of electricity.

Einstein's universe stood in stark contrast to an earlier one, where communications were carried out between people and written texts, and which relied on transportation technologies that fell under the general rubric of "the post." The post-post epoch was characterized instead by field physics that contrasted with previous action-ata-distance theories of the universe and of gravitation. Additionally, it was a world where the carriers of communication were no longer people and written texts, but electromagnetic: telegraph, telephone and radio.

\section{Conclusion}

What does Einstein's private life and his science have to do with each other? Einstein, in many of his writings, claimed that they had very little to do with each other. For example, in his autobiography he explained, "The essential in the being of a man of my type lies precisely in what he thinks and how he thinks, not in what he does or suffers." 89 Yet Einstein's thoughts, deeds and feelings were conducted through media in a manner not wholly dissimilar and sometimes directly connected to the transmission of light through space. They too could not escape inertial forces. A concern with sending and receiving affected equally Einstein's thoughts, deeds, and sufferings.

Describing a life in terms of "thinking, doing and suffering," Einstein nonetheless asked us to focus only on the first element. For the most part, historians and philoso- 
phers - until recently - seemed to agree with him, at the same time they have lamented and despaired about how difficult it is to analyze "thinking."

To overcome evident difficulties in analyzing "thinking," the philosopher Hans Reichenbach proposed one very popular solution: analyze it as it "ought" to be rather than as it really was. "What epistemology intends is to construct thinking processes in a way in which they ought to occur," he proposed. Reichenbach invited philosophers to study the "context of justification" where scientific theories were tested, instead of trying to tackle the obscure "context of discovery" of the mind's labyrinths. The legacy of Reichenbach, and the logical empiricist school of which it formed part, described a world divided in two. By "replacing the real intermediary links" between the startingpoint of knowledge and its final result with a "rational reconstruction" of those links, the internal structure of knowledge could be studied. In his rational reconstruction of Einstein's work, Reichenbach felt justified to efface its connections to media technologies at the very same time that he used those technologies to understand Einstein's work. A focus on the relation of Einstein's work to the communication technologies of his era leads us to a radical alternative that denies the neat divisions outlined by Reichenbach.

In the summer of 1901 Einstein received a letter from Marić, saying "There is a train that passes Mettmenstatten at 7:56 A.M.... Would you like to take this journey with me, sweetheart? Oh, if only I could have you once more, just exactly to my heart's desire, my dear sweet love! If you knew how I loved you." A few years later, Einstein would write down the famous lines of his relativity paper, "That train arrives here at 7 o'clock." ${ }^{90}$ Writing these lines, he was - despite himself - thinking, doing and suffering at the same time. 
I would like to thank Stefan Andriopoulos, Gerald Holton, Oliver Simons, and Matthew Stanley for their generous help, and Bernhard Siegert for inspiring me to think about the post.

1 Arthur Eddington, The Nature of the Physical World, ed. Ernest Rhys (London: J.M. Dent \& Sons Ltd., 1935 (1928)), 64. For Eddington see Matthew Stanley, Practical Mystic: Religion, Science, and A. S. Eddington (Chicago: University of Chicago Press, 2007).

2 Einstein to Elsa Einstein, Leyden, Saturday [22 May 1920] Albert Einstein Archives, Online and at the Hebrew University of Jerusalem, Israel.

3 Peter Galison, Einstein's Clocks, Poincaré's Maps: Empires of Time (New York: W.W. Norton and Company, 2003).

4 Albert Einstein, “Autobiographical Notes," in Albert Einstein: Philosopher-Scientist, ed. Paul Arthur Schilpp (La Salle, Illinois: Open Court, 1949), 55.

5 Kafka to Milena Jesenská, end March 1922, in Franz Kafka, Letters to Milena, ed. Willi Haas, trans. Tania Stern and James Stern (New York: 1953), 229. Cited in Bernhard Siegert, Relays: Literature as an Epoch of the Postal System ed. Timothy Lenoir and Hans Ulrich Gumbrecht (Stanford: Stanford University Press, 1999), 15.

6 Albert Einstein, “Zur Elektrodynamik bewegter Körper," Annalen der Physik 17 (1905).

7 Alfred North Whitehead, An Enquiry Concerning the Principles of Natural Knowledge (Cambridge: University Press, 1919), 53-54.

8 Einstein to Wilhelm Wien, Bern, 23 August [July] 1907.

9 Einstein to Wilhelm Wien, Lenk, 7 August 1907.

10 Einstein to Wilhelm Wien, Lenk, 7 August 1907.

11 Einstein to Wilhelm Wien, Lenk, 7 August 1907.

12 Lorraine Daston and Elizabeth Lunbeck, Histories of Observation (Chicago: University of Chicago Press, 2010).

13 André Metz, "Le Temps d'Einstein et la philosophie: à propos de l'ouvrage de M. Bergson, Durée et simultanéité," Revue de philosophie 31 (1924).

14 See Jimena Canales, A Tenth of a Second: A History (Chicago: Chicago University Press, 2009).

15 Many readers of Einstein have remarked on the importance of measurement in his work. What I want to add is that Einstein's work was concerned not with measurement in general but with a particular form of measurement: detection of light signals.

16 Einstein, “Über das Relativitätsprinzip und die aus demse ben gezogenen Folgerungen. "Jahrbuch der Radioaltivität und Elektronik 4: 411-462. Cited in Richard Staley, Einstein's Generation: The Origins of the Relativity Revolution (Chicago: University of Chicago Press, 2008), 311.

17 Albert Einstein, "The Principle of Relativity and Its Consequences in Modern Physics," Archives des sciences physiques et naturelles 29 (1910).

18 "Discussion," Vierteljahrsschrift Naturforschende Gesellschaft Zürich 56 (1911).

19 Whitehead, An Enquiry Concerning the Principles of Natural Knowledge, 53.

20 Ibid., 54

21 Alfred North Whitehead, "Symposium. The Problem of Simultaneity: Is there a Paradox in the Principle of Relativity in regard to the Relation of Time Measured to Time Lived?," in Relativity, Logic, and Mysticism. Aristotelian Society Supplementary Volume III (1923), 39.

22 Ibid.

23 William Pepperell Montague, "The Einstein Theory and a Possible Alternative," The Philosophical Review 33, no. 2 (1924): 151.

24 Ibid., 145

25 Gaston Bachelard, La Valeur inductive de la relativite (Paris: J. Vrin, 1929), 145
26 DeWitt H. Parker, Experience and Substance (Ann Arbor: The University of Michigan Press, 1941), 168.

27 Oliver Lodge, "The Geometrisation of Physics, and its Supposed Basis on the Michelson-Morley Experiment," Nature 106, no. 2677 (1921): 800

28 Ibid.

29 Ibid.

30 Arthur Stanley Eddington, "The Relativity of Time," Nature 106, no. 2677 (1921): 803.

31 Ibid., 804.

32 Eddington, The Nature of the Physical World, 65

33 Ibid.

34 Ibid., 66.

35 Louis de Broglie, "A General Survey of the Scientific Work of Albert Einstein," in Albert Einstein: PhilosopherScientist, ed. Paul Arthur Schilpp (La Salle, Illinois: Open Court, 1949), 113.

36 Hans Reichenbach, "The Philosophical Significance of the Theory of Relativity," in Albert Einstein: PhilosopherScientist, ed. Paul Arthur Schilpp (La Salle, Illinois: Open Court, 1949), 301.

37 Ibid., 306.

38 Ibid., 308.

39 Ibid., 301.

40 Ibid., 308.

41 Ibid., 310.

42 "If, however, one introduces as unit of time instead of the second the time in which light travels $1 \mathrm{~cm}, \mathrm{c}$ no lon ger occurs in the equations." Einstein, "Autobiographical Notes," 61

43 Cited in Paul Langevin, “'L'evolution de l'espace et du temps," Scientia 10 (1911)

44 Hendrik A. Lorentz, The Einstein Theory of Relativity: A Concise Statement (New York: Brentano's, 1920 (1919)), 61.

45 Langevin, "L'evolution de l'espace et du temps."

46 Ibid.

47 Einstein, "The Principle of Relativity and Its Consequences in Modern Physics."

48 Arthur Stanley Eddington, The Theory of Relativity and it Influence on Scientific Thought (Oxford: Clarendon Press, 1922), 17 n.1.

49 For a history of the postal system, see Siegert, Relays: Literature as an Epoch of the Postal System, 15.

50 Paul Valéry, La Conquète de l'ubiquité (Paris: 1928).

51 Élie Mascart to Poincaré, Paris, 29 October 1903. In Henri Poincaré, La correspondance entre Henri Poncaré et les physiciens, chimistes et ingénieurs (Basel: Birkhäuser, 2007), 262.

52 Lewis S. Feuer, Einstein and the Generations of Science (New York: Basic Books, 1974), 214

53 Einstein to Marić, Dahlem, 18 August 1914. Einstein mentions phone conversations in: Einstein to Marić, Mettmenstetten, 22 July 1901; Einstein to Jost Winteler, Bern, 7 February 1907; Einstein to Jakob Ehrat, Zurich, 7 January 1914.

54 Siegert, Relays: Literature as an Epoch of the Postal System, 189.

55 Carl Beck to Einstein, Chicago, 28 December 1920.

56 Einstein to Marić, Schaffhausen, 28 November 1901.

57 Einstein to Marić, Schaffhausen, 28 November 1901

58 Einstein to Marić, Melchtal, 6 August 1900.

59 Einstein to Marić, Milan, 30 August 1900 or 6 September.

60 Marić to Einstein, Zurich, 3 May 1901.

61 Einstein to Marić, Milan, 10 October 1899.

62 Einstein to Marić, Milan, 27 March 1901.

63 Einstein to Marić, Schaffhausen, 17 December 1901.

64 Einstein to Marić, Melchtal, 27 March 1901.

65 Einstein to Marić, Winterthur, c. second half of May 1901.

66 Einstein to Marić, Bern, 28 June 1902 or later.

67 Einstein to Elsa, Zurich, 16 October 1913.
68 Einstein to Elsa Einstein, Berlin, after 3 August 1914.

69 Einstein to Marić, Milan, 27 March 1901.

70 Einstein to Marić, Bern, 4 February 1902

71 Einstein to Elsa, Zurich, c. 14 March 1913.

72 Einstein to Elsa, Zurich, 3 April 1913.

73 Hans Albert Einstein to Einstein, [Zurich], [before 21 March 1921].

74 Einstein to Marić, Melchtal, 6 August 1900.

75 Einstein to Conrad Habicht, Bern, 15 April 1904.

76 Einstein to Elsa, Zurich, 2 December 1913.

77 Einstein to Elsa, Zurich, 28 January 1914.

78 Einstein to Lorentz, Berlin 25 January 1915.

79 Einstein to Elsa Einstein, Leyden, Saturday [22 May 1920].

80 Kafka to Milena Jesenská, end March 1922, in Kafka, Letters to Milena, 229. Cited in Siegert, Relays: Literature as an Epoch of the Postal System, 5.

81 Hermann Weyl, Space-Time-Matter (London: Methuen and Co., 1922), 186. Italics added.

82 Einstein to Marić, Bern, 28 June 1902 or later.

83 Einstein to Elsa Einstein, Berlin, before 30 July 1914.

84 Einstein to Elsa Einstein, Berlin, before 30 July 1914

85 Lorentz, The Einstein Theory of Relativity: A Concise Statement, 30.

86 Montague, "The Einstein Theory and a Possible Alternative," 152.

87 Ibid., 152.

88 Ibid., 152, 53.

89 For a investigation of how Einstein developed the image of an ivory tower scientist see Galison, Einstein's Clocks, Poincaré's Maps: Empires of Time.

90 Einstein, "Zur Elektrodynamik bewegter Körper." 